\title{
CORRESPONDENCE
}

Curability of breast cancer

G Y Feggetter, FRCS; $M$ Thomas, FRCS;

Diana Cairns.................6645

Early diagnosis of cancer in the head and

neck

D F N Harrison, FRCS.

Shortage of organs for transplantation

M Fox, FRCs..................646

Reticuloendothelial phagocytosis in patients with nephritis

I I Onyewotu, MD.

Rebound effect of ................646

postoperative bowel contractions

E N S Fry, FFarcs, and S Deshpande, DA . . .646

Bran content of wholemeal bread

N Fisher, PHD . . . . . . . . . . . . . . . . . 647

High-pressure medicine

E Ll Lloyd, Ffarcs; J D King, MB.......647

Geriatric patients in acute medical wards

Christine McArdle, BA.

Oxytocin and incidence of neonatal

jaundice

I G de C Chalmers, MrCog, and others . . . 647

Otitis media

V W M Drury, FRCGP. . . . . . . . . . . . . . . . 648
A place to be born

J R Ashford, PHD, and G Ferster, PHD;

J A Davis, FRCP, and others..........648

Support for varicose veins

C P Holford, FRCS . . . . . . . . . . . . . . . . 649

Liquor licensing and public health

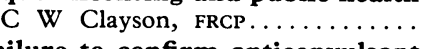

Failure to confirm anticonvulsant hypomagnesaemia

M J Stewart, PHD, Mrcpath. . . . . . . . . 649

Alleviation of IUD menorrhagia with ethamsylate

R F Harrison, FRCSED, and S Campbell,

MRCOG ...................649

Computers and privacy

Eva Bergqvist, MD . . . . . . . . . . . . . .6650

Encouragement of breast-feeding

S A Haider, MRCPED; M J Aylett, MRCGP . 650

Mobile resuscitation units

J S M Zorab, FFARCS, and P J F Baskett,

FFARCS; J S Geddes, MD, and Agnes A J

Adgey, $M D . \ldots \ldots \ldots \ldots \ldots \ldots \ldots \ldots 60 \ldots \ldots \ldots \ldots \ldots$

Sigmoid volvulus in Africa

J J Meuzelaar..................651
Infections after splenectomy in Hodgkin's disease

P L Amlot, MRCP, and J R Trounce, FRCP . . .6651

Selective induction of labour

J Bonnar, FRCOG..............651

Coitus and coronaries

J B Vergano, MRCGP . . . . . . . . . . . . . 652

Compulsory vocational training

D A Jeffs, MB; D T Herriot, MB . . . . . . 652

Consultants' ballot

G W H Jardine, FRCR . . . . . . . . . . . . . . . . 652

Distinction awards

L C Hurst, MRCPSYCH. . . . . . . . . 652

Points from letters Clinical or administrative postal addresses? (M C Joseph); Long-term digoxin treatment in general practice (D A J Firebrace); Fulminating bacterial pneumonia complicating influenza (G M Hunter); Doctors wives and the Sex Discrimination Act (Betty Gilmore); Otitis media (E O Evans); Removal of impacted rectal foreign body with obstetric forceps (H G Penman); Reticuloendothelial phagocytosis in patients with nephritis (D I

Palmer); The holiday year (A B Conyers)..653
Correspondents are urged to write briefly so that readers may be offered as wide a selection of letters as possible. So many are being received that the omission of some is inevitable. Letters should be signed personally by all their authors.

\section{Curability of breast cancer}

SIR,-I read Mr M Baum's excellent review article (21 February, p 439) and your comments on breast cancer ( $\mathrm{p}$ 414) with great interest and agree that new techniques are required to detect those metastases not revealed by routine $x$-ray investigation of the lungs and skeleton in favourable cases before treatment is begun. The whole subject is indeed gloomy, but the prognosis is not so hopeless as your assertion that only $20-30 \%$ of patients with early disease benefit from local treatment would suggest. Published results refute this and in my own small series of unselected patients with invasive carcinoma of the breast treated since 1946 and assessed in 1966 to determine the 10-20-year results I confirmed that in stage 1 cases (a) $56 \%$ were alive and free from detectable cancer, $(b)$ an additional $6 \%$ were alive but under treatment for recurrent carcinoma, (c) $26 \%$ had died of malignant disease within 10 years of operation, nearly half within 5 years, $(d) 7 \%$ had died of unconnected conditions, and $(e) 5 \%$ had been lost to follow-up. It is conceded that a few patients might have recurrence after 15,20 , or even 30 years of freedom. These patients were treated initially by radical mastectomy without radiotherapy, but in those who developed metastases all forms of therapy were given, sometimes with miraculous though temporary recession.

The early deaths from disseminated malignant disease after operation for clinically stage 1 cases cause the greatest concern; evidently these patients had undetectable metastases at the time of operation, which was of no practical benefit except the removal of the obvious lump. Some patients with small carcinomas, apparently still in stage 1 , are already doomed before medical advice is sought, and only when safe and effective cytotoxic drugs that will destroy metastases are perfected, perhaps in combination with hormone therapy, can they be saved. Indeed such drugs will ultimately make operative treatment obsolete. At present, however, the best hope for the individual woman with stage 1 carcinoma remains radical excision alone or simple amputation with radiotherapy, and additional present-day cytotoxic drugs in all cases should improve the long-term results by their effects on metastases that are already present.

Stage 2 carcinomas are not early cases and my 10-year results treated by radical excision and radiotherapy or simple amputation and radiotherapy illustrate this: (a) $17 \%$ were alive and free from detectable carcinoma (b) an additional $6 \%$ were alive with recurrent growth, (c) $70 \%$ had died of malignant disease within 10 years, and $(d) 7 \%$ had died of unrelated conditions. These results are so poo that although I disapprove, on ethical and other grounds, of blind controlled trials on surgical patients, a case could be made out to justify them in this group.

In stage 3 carcinoma not a patient survived five years with any form of treatment, and these figures emphasise the importance of diagnosis and treatment of carcinoma of the breast before stage 2 is reached.

Newcastle upon Tyne

GEORGE Y FEGGETTER

SIR,-In his article on this subject $\mathrm{Mr} M$ Baum (21 February, p 439) states his opinion that mastectomy for $70 \%$ of women with primary disease is a "futile mutilating procedure." My disagreement with this statement may best be expressed by quoting a $B M F$ leading article on the treatment of early carcinoma of breast." "If several suggested techniques give the same expectation of life, it is then necessary to define which of them gives the best chance of local control of the disease, so that even though the patient may eventually die of disseminated cancer she is a least saved the pain and suffering of local ulceration."

It is known that in the treatment of early breast cancer procedures less radical than simple mastectomy, such as sector mastectomy ${ }^{2}$ or wide local excision of the tumour, ${ }^{3}$ are associated with a significantly greater rate of local recurrence. Surely a discussion of the place of mastectomy in the cure of early breast cancer is inseparable from a consideration of the place of mastectomy in the eradication of local disease. Apart from describing the natural history of breast cancer, with invasion of chest wall and ulceration of skin, Mr Baum makes no attempt to qualify his condemnation of mastectomy in terms of the benefits of local eradication of disease.

MeIRION Thomas

\section{St James's Hospital,}

London SW 12

1 British Medical fournal, 1972, 2, 417.

Taylor, H, et al, British fournal of Surgery, 1971, 58, 161 .

Atkins, H, et al, British Medical fournal, 1972, 2, 423.

SIR,-As co-ordinator of a trial studying chemotherapy in early breast cancer, I was very interested in your leading article (21 February, $\mathrm{p}$ 414) and the article by $\mathrm{Mr} \mathrm{M}$ Baum (p 439). I welcomed especially the suggestions that breast cancer should be assumed to be metastatic until proved otherwise and that patients should be entered into one of the current trials investigating the value of systemic treatment at the time of mastectomy. 